\title{
Early Neonatal Mortality's Determinants in the Neonatology Department of Mohamed V Hospital in Tangier, Morocco
}

\author{
Ettoini Kaoutar (D), Yousra El Boussaadni (iD), Abdallah Oulmaati \\ Pediatrics Department, Mohamed V Hospital, Faculty of Medicine and Pharmacy, University of Abdelmalek Essaadi \\ Tangier, Morocco
}

\begin{abstract}
Objective: This study aims to identify the determinants of early neonatal mortality in the neonatology department of Mohamed $\mathrm{V}$ hospital in Tangier.

Material and methods: This is a prospective study including all newborns hospitalized and deceased in the pediatric department of the hospital Mohammed V from June 1 to December 31, 2019. The recorded cases were processed and analyzed by SPSS software.

Results: 529 newborns were hospitalized in the pediatric department during the study period, of which 92 died (17.39\%) between 0 and 7 days. Four leading causes justified this frequency: prematurity occupies first place (59\%), followed by perinatal asphyxia (22\%), neonatal infection (15\%) in third place, congenital malformations (3\%) in fourth place. Parturients aged between 20 and 35 years are the most affected (76\%). The majority of women (71.4\%) in our series had not undergone prenatal consultation (PNC) or had done so in insufficient numbers.

Conclusion: Neonatal mortality remains high. Improvement of this situation requires education of women, reinforcement of surveillance before, during pregnancy, during delivery, and the postpartum period, as well as effective management of premature newborns in the first week of life, should improve the neonatal prognosis by reducing the intra-hospital incidence of neonatal mortality in our setting.
\end{abstract}

KEYWORDS: Frequency - Causes - Early neonatal mortality.

Correspondence: Dr Kaoutar Ettoini, Pediatrics Department, Mohamed V Hospital, Faculty of Medicine and Pharmacy, University of Abdelmalek Essaadi, Tangier, Morocco. Email: ettoinik@gmail.com

Copyright (C) 2021 Ettoini K et al. This is an open access article distributed under the Creative Commons Attribution 4.0 International, which permits unrestricted use, distribution, and reproduction in any medium, provided the original work is properly cited.

\section{INTRODUCTION}

Neonatal mortality is an indicator of the quality of obstetric and neonatal care, and it depends on the level of socio-economic development of a country. Although neonatal mortality has been observed to decrease in most parts of the world, it is still a significant problem in developing countries [1].

According to the World Health Organization (WHO), the number of newborns who died had decreased from 4.4 million in 1990 to 2.9 million in 2010. Several African authors were interested in this subject and showed 25.4\% in the university hospital center of Blida, Algeria, 27.4\% in Dakar, Senegal, and $25.9 \%$ in Ouagadougou, Burkina Faso [2].

Neonatal mortality is a significant public health problem in the world. Of the 130 million children born each year worldwide, approximately 4 million die before their 28 th day of life, 2 million of them in the first week of life. More than 5 million children died before reaching the age of 5 , and almost half of these deaths were among newborns (from birth to 28 days) [3-5]. The factors associated with this neonatal mortality are not clearly identified.

The main objective of our study is to identify the determinants of early neonatal mortality in the neonatology department of the provincial hospital center (PHC) of Tangier.

\section{MATERIAL AND METHODS}

This prospective study includes all newborns hospitalized and who died in the pediatric department of Mohammed V hospital from June 1 to December 31, 2019. The recorded cases were processed and analyzed by SPSS software. 
During the study period, 529 newborns were hospitalized in the pediatric department, of which 92 died (17.39\%) between 0 and 7 days.

\section{Inclusion and exclusion criteria}

Neonatal mortality cases occurring between 0 and 7 days were included in this study. We excluded neonates admitted after seven days of life.

\section{Study variables}

Neonatal parameters: age (in days), weight, sex, ante- and post-natal history (place of delivery, Apgar score at the 5th minute, notion of resuscitation, Silverman score, as well as the presence of malformation), diagnosis of entry, and exit, period of death,

Sociodemographic and health parameters of the mother: age, obstetrical history, obstetrical index, followup and number of prenatal consultations (PNC), pathologies during pregnancy and labor, and delivery route.
Ethical considerations:

Our study was nonbinding. All information collected from the mother-child couple concerned was kept confidential.

\section{RESULTS}

The study collected 92 cases of early neonatal mortality out of a total of 529 newborns (born on-site or referred) admitted to the neonatology department, which gives an in-hospital frequency of $17.39 \%$ (Figure $n^{\circ} 1$ ). It also showed that $80 \%$ of deaths occurred within 24 hours of life, and $20 \%$ occurred after 24 hours.

The diagnosis of death was dominated by prematurity which is the first cause of neonatal mortality (59\%), followed by perinatal asphyxia (22\%), neonatal infection $(15 \%)$ in the third position, congenital malformations (3\%) in the fourth position, the last place is occupied by a postoperative cause $(1 \%)$. (Figure $\mathrm{n}^{\circ} 2$ )

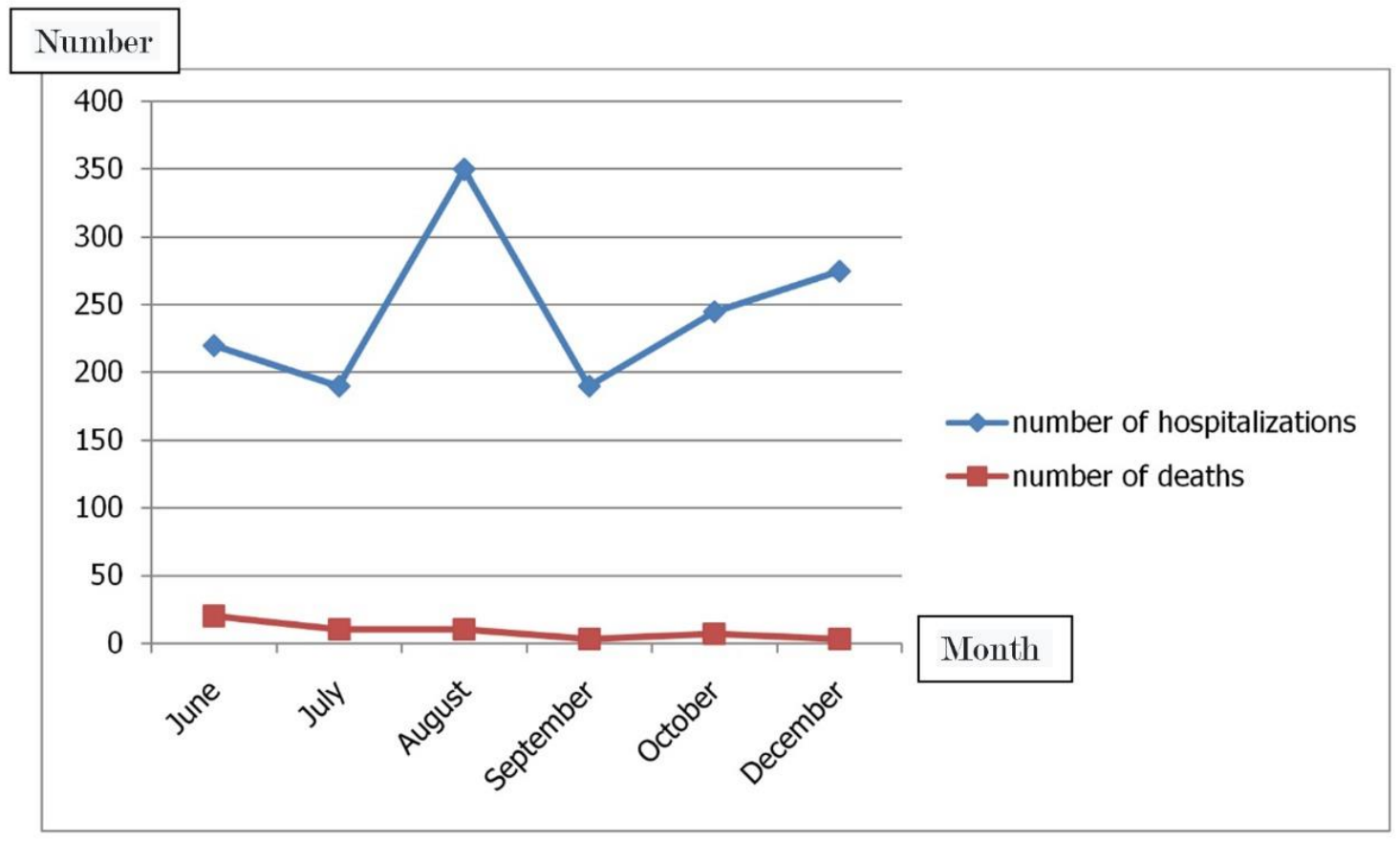

Figure $\mathbf{n}^{\circ}$ 1: Number of deaths compared to the number of neonatal hospitalizations.
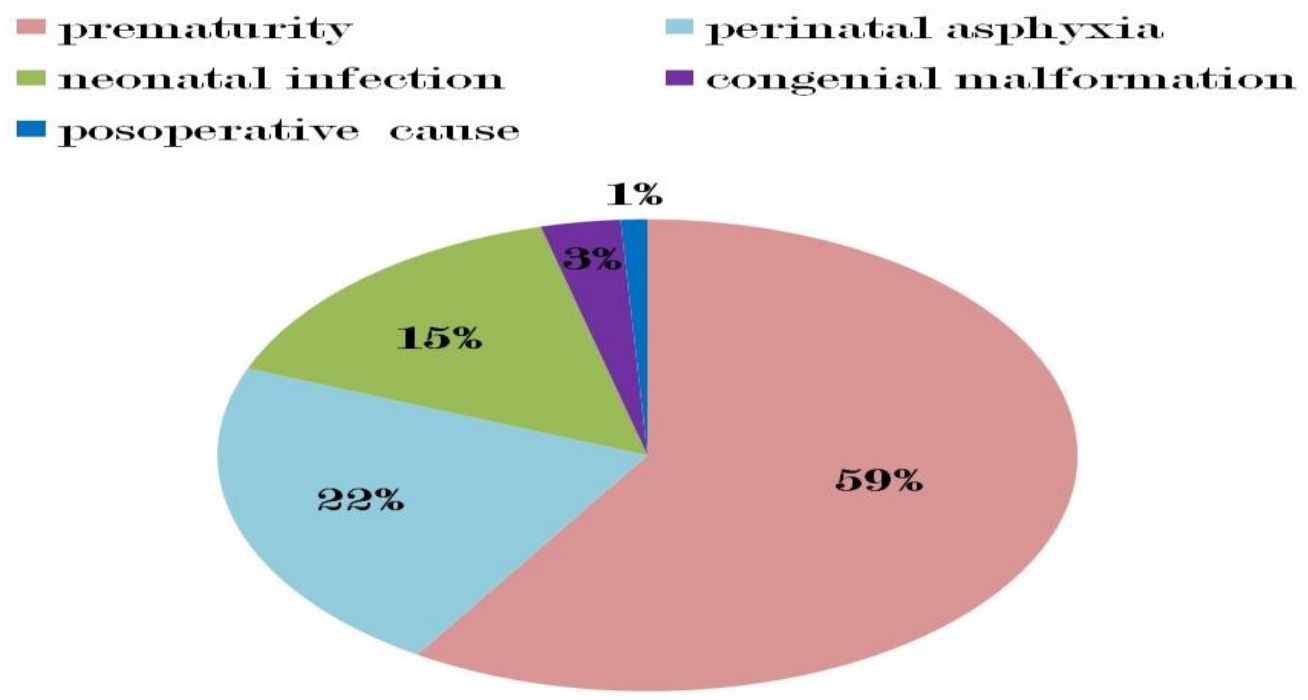

Figure n ${ }^{\circ}$ : Causes of death 
Determinants related to the parents and the follow-up of the pregnancy:

Parturients aged between 20 and 35 years are the most affected (76\%). Pregnancies are followed in $64 \%$ of cases. Urinary tract infection in $28.2 \%$. (Table $\mathrm{n}^{\circ} 1$ )

Table 1: Determinants related to parents and pregnancy follow-up

\begin{tabular}{lcc}
\multicolumn{3}{c}{ pregnancy follow-up } \\
\hline Variable & $\begin{array}{l}\text { Number } \\
(\mathbf{n = 9 2 )}\end{array}$ & Percentage \% \\
\hline Maternal age & & \\
$<$ 20 years & 10 & 11 \\
20à 35 years & 70 & 76 \\
$>$ 35 years & 12 & 13 \\
\hline Parity & & \\
Primiparous & 16 & 17 \\
multiparous & 76 & 83 \\
\hline
\end{tabular}

\begin{tabular}{lll}
$\begin{array}{l}\text { Pathology during } \\
\text { pregnancy }\end{array}$ & & \\
Urinary tract & 26 & $28,2(\mathrm{p}<0,005)$ \\
infection & 8 & 8,6 \\
diabetes ton & 3 & 3,26 \\
Pregnancy toxicity & 1 & 1,08 \\
$\begin{array}{l}\text { Genital infection } \\
\text { cardiopathies }\end{array}$ & 1 & 1,08 \\
\hline number of & & \\
prenatal visits & & \\
0 & 9 & $10(\mathrm{p}<0,005)$ \\
1à3 & 24 & 26 \\
$>=4$ & 59 & 64 \\
\hline
\end{tabular}

Determinants related to delivery and the newborn:

Poor adaptation to extra uterine life was noted in $24 \%$ of cases, prematurity in $59 \%$ of newborns, low birth weight $<1500 \mathrm{~g}$ in $38 \%$. (Table $\mathrm{n}^{\circ} 2$ )

\section{DISCUSSION}

Our study, despite its limitations, has allowed us to know some risk factors and causes of neonatal mortality in Tangier hospital center.

To prevent the occurrence of deaths of newborns at risk and to improve their survival, some authors [6] advocate the promotion of adequate nutrition to the mother, the prevention and management of infection during pregnancy, and the use of the kangaroo method in hypertrophic babies.

We found that newborns born to mothers with low levels of education were at least twice as likely to die. Several authors have shown that maternal illiteracy is a significant risk factor for neonatal mortality [6-8]. Indeed, educated mothers tend to have a good follow-up of the pregnancy, a good lifestyle, and diet, easy access to quality health care, and are more aware of the danger signs in the baby.

As we have found, several authors have cited a lack of pregnancy monitoring as a risk factor associated with neonatal mortality $[6,9,10,11]$. Indeed, good pregnancy monitoring allows for detecting and treating pregnancy complications that often lead to perinatal mortality [12].

A low Apgar score at the fifth minute, respiratory distress, and altered consciousness at birth were the most lethal risk factors in our study. These situations are primarily due to very dystocic deliveries $[12,13]$ and expose the newborn to asphyxia and neonatal infection, which several authors consider as the main causes of neonatal death $[6,9,7,14]$. We did not find an association between maternal age and neonatal mortality. However, some authors $[11,12,15]$ have reported a strong association between maternal age and neonatal death, especially in the age range [15-20 years]. This age group is made up of adolescents and primiparous women who are prone to dystocic deliveries. About half (46\%) of our patients had died within the first 24 hours. This is similar to the $53.3 \%$ of Tachiyeka et al. [14] and 56\% of Adetola et al. in Nigeria [6].

Table 2: Determinants related to childbirth and the

\begin{tabular}{lll}
\hline \multicolumn{2}{l}{ newborn } & \\
\hline Variable & $\begin{array}{l}\text { Number } \\
(\mathbf{n = 9 2})\end{array}$ & $\begin{array}{l}\text { Percentag } \\
\mathbf{\%}\end{array}$ \\
\hline Way of delivery : & & \\
vaginal delivery & 48 & 48 \\
cesarean section & 44 & 52 \\
\hline Adaptation $\quad$ to & \\
extrauterine life: & & \\
Apgar <7 (5th minute) & 22 & $24(\mathrm{p}<0,005)$ \\
Apgar >7 (5th minute) & 52 & 56 \\
Apgar unknown & 18 & 20 \\
\hline
\end{tabular}

\begin{tabular}{lll}
$\begin{array}{l}\text { Resuscitation in the } \\
\text { birth room : }\end{array}$ & & \\
yes & 62 & $68(\mathrm{p}<0,005)$ \\
no & 30 & 32 \\
\hline Gestational age: & & \\
22 WA à 28 WA & 6 & $6(\mathrm{p}<0,005)$ \\
28 WA à 34 WA & 32 & $36(\mathrm{p}<0,005)$ \\
34 WA à 37 WA & 16 & 17 \\
>=37WA & 38 & 41 \\
\hline $\begin{array}{l}\text { Antepartum } \\
\text { corticosteroid }\end{array}$ & 66 & $71(\mathrm{p}<0,005)$ \\
therapy not taken in & & \\
preterm infants & & \\
\hline $\begin{array}{l}\text { Birth weight } \\
\text { <1500g }\end{array}$ & 35 & $38(\mathrm{p}<0,005)$ \\
1500g à 2499g & 37 & 40 \\
2500g à 3499g & 17 & 19 \\
$>=3500 \mathrm{~g}$ & 3 & 3 \\
\hline $\begin{array}{l}\text { Admission } \\
\text { Direct }\end{array}$ & 61 & 66 \\
Referral & 31 & 34 \\
\hline
\end{tabular}

In our series, neonatal deaths were dominated by four leading causes, prematurity and its complications, neonatal infections, polymalformative syndrome, and neonatal asphyxia. These findings are almost in line with those of the World Health Organization (WHO), showing that prematurity and its complications are the first cause of neonatal mortality and those of the authors of many studies relating to Black Africa. Conversely, in other studies, neonatal infections, respiratory distress, or asphyxia have been shown to be the leading cause of neonatal mortality [16-19].

The majority of women $(71.4 \%)$ in our series had not undergone prenatal consultation (PNC) or had done so in insufficient numbers. This has serious consequences, given that this consultation is an activity that leads to the prevention of several deplorable situations such as maternal infections (urogenital infections, malaria, etc.), as confirmed by our study, which can lead to neonatal infections, prematurity, abortion, stillbirths and low birth weight $[1,20]$.

Referring to the birth weight of newborns, our study showed that $59.2 \%$ of cases had low birth weight. Similar 
to those reported by Shrimton and Araujo in Brazil, these results are located between the low and high values reported in the literature [1].

According to the WHO, in terms of survival during the neonatal period, girls have a biological advantage such as faster lung maturation than male children and a lower risk of respiratory complications $[1,21]$.

A percentage of $58.3 \%$ of pregnancies were followed. Yet, according to WHO (2016) and worldwide, followed pregnancies represent $64 \%$. According to WHO, twothirds of deaths are from unattended pregnancies. Similarly, in Marrakech, Hanafi pointed out that the rate of unattended pregnancies reached $66 \%[2,22,23]$.

A slight predominance of the male sex $(58.7 \%)$ in neonatal deaths is noted. Indeed, according to WHO (2006), girls have a well-described biological survival advantage during the neonatal period since the ratio of boys to girls in neonatal mortality in developed countries is 1.3. Compaore in 2009 and Harir in 2014 concluded that the male gender is more affected by mlneonatal mortality $[23,24]$

A percentage of $57.14 \%$ of the deaths concerned birth weight between $500 \mathrm{~g}$ and $2400 \mathrm{~g}$. These results are consistent with Compaore (2009), who reported that $75.3 \%$ of deaths in the early neonatal period occur in low birth weight infants. Also, Ongoiba (2010) noted that 57\% weighted less than 2500 grams $(\mathrm{g})$.

\section{AUTHORS' CONTRIBUTIONS}

All the authors have actively participated in the redaction, the revision of the manuscript, and provided approval for this final revised version.

\section{REFERENCES}

[1] Kalonji DC, Mbayo PM, Kembo LN, Ngombe MI, Ngimbi SL, Nkulu HK, et al. Fréquence et causes de la mortalité néonatale précoce à Kamina, République Démocratique du Congo. Rev l'Infirmier Congolais. 2018 ; 2(2): 90-94. [Accessed 2021 Nov 05]. Available from: https://www.revue.istmlubumbashi.net/wpcontent/uploads 12019/05/Fr\%C3\%A9quence-et-causes-de-lamortalit\%C3\%A9-n\%C3\%A9onatale-pr\%C3\%A9coceRIC-2018-2-2.pdf

[2] Oumar MO. La mortalité néonatale au CHU Hassan II de Fès: Etude rétrospective à propos de 235 cas. [Thèse], Maroc. 2010. [Accessed 2021 Nov 05]. Available from: http://www.chu-fes.ma/la-mortalite-neonatale-au-chuhassan-ii-de-fes-etude-retrospective-a-propos-de-235-cas/

[3] Garba M, Kamaye M, Alido S, Zoubeiro H, Oumarou Z, Amadou A. Les déterminants de la mortalité néonatale précoce à la maternité Issaka-Gazobi de Niamey. J Pédiatrie puériculture. 2017 Sep: 30(4):156-161. DOI: $10.1016 /$ j.jpp.2017.01.005

[4] Ahmed OB, Lopez AD, Inoeu M. The decline in child mortality: a reappraisal. Bull World Health Organ. 2000; 78(10):1175-91.

[5] Levels and Trends in Child Mortality. United Nations InterAgency Group for Child Mortality Estimation (UN IGME), Report 2020. Sep 2020. [Accessed 2021 Nov 05]. Available from: https://data.unicef.org/resources/levelsand-trends-in-child-mortality/

[6] Adetola AO, Tongo OO, Orimadegun AE, Kike Osinusi. Neonatal mortality in an urban population in Ibadan Nigeria. Pediatr Neonatol. 2011 Oct; 52:243-50. DOI: $10.1016 /$ j.pedneo.2011.06.001

[7] Muluken G, Mitike M, Wubegzier M. Trends and risk factors for neonatal mortality in Butajira District, South
Infection was present in $25.8 \%$ of the deceased newborns. These results confirm Compaore (2009), who stated that $45.5 \%$ had moderate respiratory distress. [23]

Preterm death occurred in $61.9 \%$, half of whom were born between 28 and 34 weeks of amenorrhea. In 2014, Blencowe related that prematurity had become the leading cause of death in children under five years old. Similarly, Harir (2014) and Compaore (2009) revealed a prematurity rate of $89 \%$ and $40.1 \%$ of cases, respectively [23].

The low birth route predominates with $82.14 \%$ of cases compared (2009), and Ongoiba (2010) states that vaginal delivery predominates in the cases of deaths with $75.6 \%$ and $74 \%$, respectively. The results of Harir (2014) differ entirely, as a cesarean section was the most practiced for mothers of deceased newborns $(65.83 \%)$ [23].

\section{CONCLUSION}

Neonatal mortality remains high. The improvement of this situation requires women's education, strengthening of monitoring before, during pregnancy, during delivery, and the postpartum period. As well as effective management of premature newborns in the first week of life should improve the neonatal prognosis by reducing the intrahospital frequency of neonatal mortality in our environment.

\section{CONFLICT OF INTEREST}

Authors have no conflicts of interest to declare.

Central Ethiopia, (1987-2008): a prospective cohort study. BMC Pregnancy Childbirth. 2014 Feb 11; 14:64. DOI:10.1186/1471-2393-14-64

[8] Rahman S, Salameh K, Bener A, El Ansari W. Socioeconomic associations of improved maternal, neonatal and perinatal survival in Qatar. Int $\mathrm{J}$ Womens Health. 2010 Sep 17; 2:311-8. DOI: 10.2147/ijwh.s12426

[9] Mengesha HG, Wuneh AD, Lerebo WT, Tekle Tesfay. Survival of neonates and predictors of their mortality in Tigrayregion, Northern Ethiopia: prospective cohort study. BMC Pregnancy Childbirth. 2016 Aug 2;16(1):202. DOI: 10.1186/s12884-016-0994-9

[10] Sidibé T, Sangho H, Doumbia S, Sylla M, Keita M, Keita HD, et al. Mortalité néonatale dans le district sanitaire de Kolokani(Mali). J Pédiatrie Puériculture. 2006;19:272-6. DOI: 10.1016/j.jpp.2006.08.004

[11] Mekonnen Y, Tensou B, Telake DS, Tedbabe Dgefie, Abeba Bekele. Neonatal mortality in Ethiopia: trends and determinants. BMC Public Health 2013 May 17; 13:483. DOI: $10.1186 / 1471-2458-13-483$

[12] Akinyemi JO, Bamgboye EA, Ayeni O. Trends in neonatal mortality in Nigeria and effects of bio-demographic and maternal characteristics. BMC Pediatr. 2015 Apr 9; 15:36. DOI: $10.1186 / \mathrm{s} 12887-015-0349-0$

[13] Lukonga E, Michelo C. Factors associated with neonatal morta-lity in the general population: evidence from the 2007 Zambia Demographic and Health Survey (ZDHS); a cross sectio-nal study. Pan Afr Med J. 2015 Jan 23; 20:64. DOI: $10.11604 /$ pamj.2015.20.64.5616

[14] Tachiweyika E, Gombe N, Shambira G, Chadambuka A, Mufuta T, Zizhou S. Determinants of perinatal mortality inMarondera district, Mashonaland East Province of Zimbabwe, 2009: a case control study. Pan Afr Med J. 2011; 8:7. DOI:10.4314/pamj.v8i1.71054 
[15] Carlo WA, Travers CP. Maternal and neonatal mortality: time to act. J Pediatr (Rio J). Nov-Dec 2016; 92(6):543545. DOI:10.1016/j.jped.2016.08.001

[16] Chiabi A, Takou V, Mah E, Nguefack S, Siyou H, Takou V, et al. Risk Factors for Neonatal Mortality at the Yaounde Gynaeco-Obstetric and Pediatric Hospital, Cameroon. Iran J Pediatr. 2014 Aug; 24(4):393-400.

[17] Katamea T, Mukuku O, Kamona L, Mukelenge K, Mbula $\mathrm{O}$, Baledi L, et al. Facteurs de risque de mortalité chez les nouveau-nés transférés au service de néonatologie de l'hôpital Jason Sendwe de Lubumbashi, république démocratique Congo. Pan Afr Med J. 2014 Oct 17; $19: 169$. DOI:10.11604/pamj.2014.19.169.4018

[18] Ntambue A, Malonga F, Dramaix Wilmet M, Donnen P. La mortalité périnatale : ampleur et causes à Lubumbashi, République démocratique du Congo. Rev Epidemiol Sante Publique. 2013;61(6):5-6. DOI: $10.1016 / j . r e s p e .2013 .07 .684$

[19] Mmbaga BT, Lie RT, Olomi R, Mahande MJ, Kvåle G, Daltveit AK. Cause-specific neonatal mortality in a neonatal care unit in Northern Tanzania: a registry based cohort study. BMC Pediatr. 2012 Aug 7; 12:116. DOI: $10.1186 / 1471-2431-12-116$

[20] OMS. La mortalité néonatale baisse trop lentement, surtout en Afrique. 2011; 12. [Accessed 2021 Nov 05]. Available from: https://www.infirmiers.com/actualites/actualites/la- mortalite-neonatale-baisse-trop-lentement-surtout-enafrique.html

[21] Azoumah KD, Balaka B, Aboubakari A, Matye k, Youlou $\mathrm{A}$, Agbère AD. Morbidité et mortalité néonatales au CHU Kara (Togo). Med Afr Noire. 2010;55(2):109-12.

[22] Organisation Mondiale de la Santé, 7 novembre 2016. « Les femmes enceintes doivent pouvoir bénéficier de soins adaptés au bon moment », GENÈVE : Librairie de l'Organisation Mondiale de la Santé. [Accessed 2021 Nov 05]. Available from : https://www.who.int/fr/news/item/07-11-2016-pregnantwomen-must-be-able-to-access-the-right-care-at-the-righttime-says-who

[23] Bouzid J.Study of riqk factors os neonatal mortality in the neonatology unit at Pagnon mother-child hospitalin Meknes (morocco). EWASH \& TI Journal. 2019; 3 (1):7580. DOI:10.48421/IMIST.PRSM/ewash-ti-v3i1.15523

[24] Takou Tsapmene V. Facteurs de risque de la mortalité néonatale à l'Hôpital gynéco- obstétrique et pédiatrique de Yaoundé. [Thèse] .Faculté de médecine et des sciences biomédicales Université de Yaoundé I. 2012. [Accessed 2021 Nov 05]. Available from: https://www.memoireonline.com/01/14/8588/Facteurs-derisque-de-la-mortalite-neonatale--1-Hpital-gynecoobstetrique-et-pediatrique-d.html 